\title{
Endostatin and irradiation modifies the activity of ADAM10 and neprilysin in breast cancer cells
}

\author{
ESRA ARSLAN AYDEMIR ${ }^{1}$, ECE ŞIMŞEK $^{2}$, AYLIN FIDAN KORCUM ${ }^{3}$ and KAYAHAN FIŞKIN ${ }^{2}$ \\ ${ }^{1}$ Department of Biology, Science Faculty; ${ }^{2}$ Department of Nutrition and Dietetics, Antalya School of Health; \\ ${ }^{3}$ Department of Radiation Oncology, School of Medicine, Akdeniz University, Antalya 07058, Turkey
}

Received December 10, 2015; Accepted June 6, 2016

DOI: $10.3892 / \mathrm{mmr} .2016 .5463$

\begin{abstract}
Angiogenesis, the formation of new blood vessels, is regarded as a key cancer cell property. Endostatin (ES) is a potential antiangiogenic agent and it may be useful when implemented in combination with other cancer therapeutic strategies. The present study investigated the in vitro effects of $\mathrm{ES}$, radiotherapy $(\mathrm{RT})$ or combination therapy $(\mathrm{ES}+\mathrm{RT})$ on two important proteases, a disintegrin and metalloproteinase domain-containing protein 10 (ADAM10) and neprilysin (NEP) in 4T1 mouse breast cancer cells and the more metastatic phenotype of 4THMpc breast cancer cells. 4T1 and 4THMpc cells were treated with recombinant murine ES (4 $\mu \mathrm{g} / \mathrm{ml})$ alone, RT (45 Gy) alone or with ES + RT. ADAM10 enzyme activity was determined using a tumor necrosis factor- $\alpha$ converting enzyme ( $\alpha$-secretase) activity assay kit, and NEP enzyme activity was measured with a fluorometric assay based on the generation of free dansyl-D-Ala-Gly from $\mathrm{N}$-dansyl-Ala-Gly-D-nitro-Phe-Gly, the substrate of NEP. Western blotting analysis was performed to determine whether the altered enzyme activity levels of the two cell lines occurred due to changes in expression level. These data indicate that ES independently potentiates the activity of ADAM10 and NEP enzymes in 4T1 and 4THMpc breast cancer cells.
\end{abstract}

\section{Introduction}

Tumor growth depends on the formation and maintenance of a vascular network in neoplastic tissues to ensure delivery of oxygen and nutrients to malignant cells. The growth of new blood vessels from existing ones, termed angiogenesis, is a multifactorial process required for the growth and metastasis of tumors. Growing tumors have to stimulate new blood vessel formation in order to obtain sufficient oxygen and nutrients

Correspondence to: Dr Esra Arslan Aydemir, Department of Biology, Science Faculty, Akdeniz University, Dumlupınar Avenue, Antalya 07058, Turkey

E-mail: esra@akdeniz.edu.tr

Key words: ADAM10, ${ }^{60} \mathrm{Co}$ irradiation, endostatin, neprilysin, substance $\mathrm{P}$ and to discard of waste products. Inhibition angiogenesis is a promising strategy in cancer therapy $(1,2)$.

Targeting angiogenesis may add to the therapeutic effect conventional cancer therapeutic strategies, including chemotherapeutic agents and radiation therapy, as they are not yet entirely effective against cancer. Angiogenesis is stringently controlled via the balance of pro-angiogenic and anti-angiogenic factors, which are diffusible chemical signal molecules secreted from tumor cells. Angiogenesis may be initiated by altering the net balance between positive and negative regulators via increased production of any one of the positive regulators of angiogenesis, including vascular endothelial growth factor (VEGF), fibroblast growth factor-2, interleukin-8, placental growth factor, trans-forming growth factor (TGF) $\beta$, platelet derived growth factor, or angiopoietins, or downregulation of endogenous inhibitors of angiogenesis, including endostatin (ES), angiostatin and thrombospondin (3). Thus, it is possible to suppress angiogenesis adequately by enabling the predominance of anti-angiogenic factors surrounding the tumor. Anti-angiogenic therapy would also allow administration of anti-cancer therapeutic agents at a lower dose for shorter periods compared with conventional therapies (4).

ES was first identified in and purified from conditioned medium of cultured murine hemangioendothelioma cells in 1997 as a 20-kDa non-collagenous, proteolytically cleaved carboxyl-terminal fragment of collagen XVIII, a basement membrane and vessel wall protein. Generation of ES from collagen XVIII involves numerous proteases, including cathepsin L, elastase and matrilysin $(5,6)$. ES exerts its anti-angiogenic activity either by inhibiting endothelial cell adhesion, migration, and proliferation or by inducing apoptosis. ES has been demonstrated to inhibit endothelial cell proliferation, migration, and survival partially by blocking VEGF receptor 2 signaling, repressing Wnt signaling, activating caspase- 9 and inhibiting B-cell lymphoma 2, B-cell lymphoma-extra large by destabilizing the structure of $\beta$-catenin, and by altering the $\beta$-catenin/vascular endothelial cadherin interactions in inter-endothelial cell junctions (5,7-10). Furthermore, ES has been shown to regulate a range of genes that suppress angiogenesis, and to inactivate metalloproteinases $(11,12)$. Matrix metalloproteinases (MMPs) are proteolytic zinc-dependent endopeptidases involved in cancer progression. They are important in cancer cell growth, migration, invasion and metastasis. They degrade basement membranes 
and facilitate the invasion of cancer cells. Notably, they may also generate novel peptides and/or proteins that have different functions than their precursors (13).

Cell surface neutral endopeptidases, also termed EC3.4.24.11, enkephalinase, cluster of differentiation (CD)10 or neprilysin (NEP) is important in the degradation of amyloid $\beta$ peptides $(\mathrm{A} \beta)$, a characteristic feature of Alzheimer's disease (AD) (14). NEP is also important in pulmonary development, inflammation and injury (15). Furthermore, NEP has been demonstrated to contribute to tumor progression in human lung, prostate and breast cancer (15-19).

A disintegrin and metalloproteinases (ADAMs) have been described as membrane-anchored cell surface proteins consisting of $>40$ identified family members in the mammalian genome (20,21). Among all ADAM proteins, only 12 ADAM genes encode for proteinase activities, these are ADAM8, 9, $10,12,15,17,19,20,21,28,30$ and 33. ADAM10 and 17 are the most extensively examined family members (21). ADAM17 is known to release soluble tumor necrosis factor- $\alpha$ (TNF- $\alpha$ ) from its membrane precursor, thus called tumor necrosis factor- $\alpha$ convertase (TACE). It is reported that ADAM9, ADAM10 and ADAM17 cleave amyloid precursor protein at the $\alpha$-secretase processing site by their $\alpha$-secretase activity (22).

ADAM10 and NEP enzymes hydrolyze substance P (SP) at identical sites (23). SP is a member of the tachykinin family, encoded by the preprotachykinin Al gene (24) and has been indicated to be involved in the generation or progression of various physiological and pathophysiological conditions, including pain and depression, in addition to a variety of neurodegenerative disorders, such as AD, Parkinson's disease, Huntington's disease, and schizophrenia (25-28). In additions to the function of SP as a neurotransmitter and neuromodulator (29), SP also stimulates cell proliferation of various normal and neoplastic cell types in vitro (30). Although SP is considered to be associated with carcinogenesis, the role of SP appears to be bidirectional on inflammation, tumor growth and carcinogenesis as the intact peptide is tumorigenic and induces inflammation, whereas the hydrolysis fragments produced by peptidases are antitumorigenic and anti-angiogenic (31).

Previously, we reported that ES inhibits the in vitro growth of breast cancer cells and potentiates the anti-tumor effects of radiotherapy (RT) at appropriate doses via alteration of the quantity of substance $\mathrm{P}$ (32). The aim of the present study is to elucidate whether ES, either alone or in combination with RT, is able to alter the activity and/or expression level of ADAM-10 and NEP, which are termed SP degrading proteases.

\section{Materials and methods}

Recombinant murine ES. Recombinant murine ES, expressed in Pichia pastoris, in citrate phosphate buffer (17 mM citric acid, $66 \mathrm{mM}$ sodium phosphate dibasic, $59 \mathrm{mM}$ sodium chloride, at $\mathrm{pH}$ 6.2) was purchased from Sigma-Aldrich (St. Louis, MO, USA). The ES was thawed, gently mixed and aliquoted into standard micro Eppendorf tubes in quantities of $10 \mu \mathrm{l}$ for daily assays. These aliquots were stored at $-70^{\circ} \mathrm{C}$ until needed.

Cell lines and in vitro culture conditions. The 4T1 breast cancer cells and 4THMpc (4T1 heart metastases post-capsaicin) cell line derived from cardiac metastases of 4T1 cells were used in the present study. The two cell lines were provided by Dr Nuray Erin at Akdeniz University, Medicine Faculty (Antalya, Turkey). The cells were grown in Dulbecco's modified Eagle's medium/F12 (Invitrogen; Thermo Fisher Scientific, Inc., Waltham, MA, USA) supplemented with 5\% fetal bovine serum (Invitrogen; Thermo Fisher Scientific, Inc.), $2 \mathrm{mM}$ L-glutamine, $1 \mathrm{mM}$ sodium pyruvate, and $0.02 \mathrm{mM}$ non-essential amino acids. The cell lines were maintained at $37^{\circ} \mathrm{C}$ in a humidified atmosphere of $5 \% \mathrm{CO}_{2}$. Cells were passaged at $80-90 \%$ confluency using a 2 mM EDTA solution in $\mathrm{Ca}^{2+} \mathrm{Mg}^{2+}$ free Dulbecco's phosphate-buffered saline (PBS). All cell lines used in the current study were tested and demonstrated to be free of mycoplasma contamination (32).

Radiotherapy. Each cell plate (2-cm thick) was irradiated in the Co-60 teletherapy unit at a distance of $100 \mathrm{~cm}$. To achieve a homogeneous dose $(+2.5 \%)$ at the cell plate, the plate was embedded in water equivalent bolus material and a $0.5-\mathrm{cm}$ thick bolus material was placed on the cover of the plate. The optimal dose of irradiation was found to be $45 \mathrm{~Gy}$ at $1.5 \mathrm{~cm}$ (in the center of the plate) and the dose rate at RT was $\sim 145 \mathrm{cGy} / \mathrm{min}$ (32).

Determination of the cytotoxic dose. The cytotoxic effect of ES alone or in combination with RT on 4T1 and 4THMpc mouse breast cancer cell lines was determined in our previous study using the MTT colorimetric assay (Promega Corporation, Madison, WI, USA), the trypan blue dye exclusion method (Sigma-Aldrich) and the LIVE/DEAD ${ }^{\circledR}$ Cell Viability assay (Invitrogen; Thermo Fisher Scientific, Inc.) following 24, 48 and $72 \mathrm{~h}$ of incubation. An EnzCheck ${ }^{\circledR}$ Caspase-3 Enzyme Activity assay (Thermo Fisher Scientific, Inc.) was also performed to determine whether ES and RT, alone or in combination result in apoptosis (32).

Assay of $\alpha$-secretase activity. $\alpha$-Secretase activity was measured using a fluorimetric SensoLyte ${ }^{\text {TM }} 520$ TACE $(\alpha-$ Secretase) Activity assay kit (AnaSpec Inc., Fremont, CA, USA) according to the manufacturer's protocols. Briefly, cells were seeded into sixteen different petri dishes (100x20 mm) at a density of $3 \times 10^{5} \mathrm{cell} / \mathrm{ml}$. After $24 \mathrm{~h}, 4 \mu \mathrm{g} / \mathrm{ml}$ ES was added to only eight of sixteen petri dishes. After $4 \mathrm{~h}$, the control, RT, and ES + RT petri dishes were irradiated with $45 \mathrm{~Gy}{ }^{60} \mathrm{Co}$. Following incubation for $24 \mathrm{~h}$, cells were homogenized in lysis buffer (containing $50 \mathrm{mM}$ Tris- $\mathrm{HCl} \mathrm{pH} 7.6$, $150 \mathrm{mM} \mathrm{NaCl}, 5 \mathrm{mM} \mathrm{CaCl}_{2}, 0.05 \%$ Brij-35, $0.02 \% \mathrm{NaN}_{3}$, and $1 \%$ Triton $\mathrm{X}-100)$, and centrifuged at $12,000 \mathrm{x}$ g for $10 \mathrm{~min}$ at $4^{\circ} \mathrm{C}$. The supernatants were collected and the protein contents of samples were determined by Bio-Rad Protein assay kit (Bio-Rad Laboratories, Inc., Hercules, CA) based on the Bradford method. Equal quantities of total protein $(100 \mu \mathrm{g})$ was mixed with assay buffer and TACE substrate to a final volume of $100 \mu \mathrm{l}$. The change in fluorescence was continuously monitored with a luminescence spectrometer (Model LS55; PerkinElmer, Inc., Beaconsfield, UK) at excitation wavelength of $490 \mathrm{~nm}$ and emission wavelength of $520 \mathrm{~nm}$.

Assay of NEP activity. ES and/or RT were administered in the same manner as described above. At the end of incubation 
period, mediums were removed and cells were mechanically harvested using $500 \mu 1$ sterile PBS and a cell scraper (BD Biosciences, Franklin Lakes, NJ, USA). Cells were homogenized in $250 \mu \mathrm{l}$ of $50 \mathrm{mM}$ Tris- $\mathrm{HCl}$ buffer ( $\mathrm{pH} 7.4)$. The homogenate was then centrifuged at $1,000 \mathrm{x} \mathrm{g}$ for $10 \mathrm{~min}$ at $4^{\circ} \mathrm{C}$ to remove crude debris and to collect supernatants. The protein concentration of the samples was determined with a Bio-Rad Protein assay kit and measured against bovine serum albumin (Invitrogen; Thermo Fisher Scientific, Inc.) standards. The activity of NEP was determined as described previously with minor modifications (33). Briefly, substrate solutions consisting of $1 \mathrm{mM}$ DAGPNG and $10 \mathrm{mM}$ enalaprile in $50 \mathrm{mM}$ Tris- $\mathrm{HCl}$ with and without the addition of $10 \mathrm{mM}$ phosphoramidon, a NEP inhibitor (19), were prepared. The substrate solutions were pre-incubated at $37^{\circ} \mathrm{C}$ for $20 \mathrm{~min}$. The samples $(50 \mu \mathrm{g})$ were then incubated at $37^{\circ} \mathrm{C}$ for $20 \mathrm{~min}$ with $100 \mathrm{ml}$ of each substrate solution. The reaction was stopped by boiling for $10 \mathrm{~min}$ at $90^{\circ} \mathrm{C}$. The samples were then diluted 1:10 with $50 \mathrm{mM}$ Tris- $\mathrm{HCl}$ and spun for $5 \mathrm{~min}$ in a microfuge at $13,190 \times \mathrm{g}$ at $4^{\circ} \mathrm{C}$. The change in fluorescence of the supernatants was monitored with a luminescence spectrometer (Model LS55) at an emission wavelength of $562 \mathrm{~nm}$ and an excitation wavelength of $342 \mathrm{~nm}$.

Western blotting. To investigate whether changes in NEP and ADAM10 activities of 4T1 and 4THMpc cells were due to changes in protein content, cell homogenates were assayed by western blotting as described previously (32). Briefly, $25 \mu \mathrm{g}$ of homogenate protein were separated on a $10 \%$ acrylamide gel by SDS-PAGE and then transferred to polyvinylidene difluoride membranes (Hybond-P; GE Healthcare Life Sciences, Little Chalfont, UK) with a semi-dry transfer apparatus. The membranes were blocked with $5 \%$ milk in Tris-buffered saline and then probed with rabbit polyclonal anti-NEP (1:2,000; EMD Millipore, Billerica, MA, USA; cat. no. AB5458) or polyclonal anti-ADAM10 (1:1,000; EMD Millipore; cat. no. AB19026) at room temperature for $1 \mathrm{~h}$. The membranes were washed four times with Tris-buffered saline and Tween 20 solution. The primary antibody was detected with horseradish peroxidase-conjugated goat anti-mouse secondary antibody (1:10,000 for ADAM10, 1:20,000 for NEP; Santa Cruz Biotechnology, Santa Cruz, CA; cat. no. sc-2005) and the blots were visualized with a chemiluminescent substrate (ECL Plus kit; GE Healthcare Life Sciences) and exposure to film (Sigma-Aldrich). Kaleidoscope ${ }^{\mathrm{TM}}$ protein standards (Bio-Rad Laboratories, Inc.) were used to determine the molecular weights of the visualized bands.

Statistical analysis. All data are presented as the mean \pm standard error of the mean. Data analysis was performed using a Instat 3.1 professional statistics software program (Graph Pad Software, Inc., La Jolla, CA, USA). Analysis of variance with Dunnett's multiple comparisons post-test and t-tests (for comparisons between two groups) were used for intergroup comparisons. The graphs were drawn using Sigma Plot version 10.0 (Systat Software, Inc., Chicago, IL, USA) and CorelDRAW version X5 (Corel Corporation, Ontario, ON, Canada). $\mathrm{P}<0.05$ was considered to indicate a statistically significant difference.

\section{Results}

Determining the cytotoxic effects of ES alone or in combination with $R T$. In our initial study, different concentrations of ES $(0.5,1,2,4$ and $8 \mu \mathrm{g} / \mathrm{ml})$ and different fractions of irradiation $\left(5-45 \mathrm{~Gy}{ }^{60} \mathrm{Co}\right)$, either alone or in combination, were tested to determine the optimum cytotoxic doses for 4T1 and 4THMpc breast cancer cells. According to four different cytotoxicity test results, $4 \mu \mathrm{g} / \mathrm{ml} \mathrm{ES}$ and $45 \mathrm{~Gy}{ }^{60} \mathrm{Co}$ irradiation exhibited the most notable cytotoxic effect on the 4T1 and 4THMpc cell lines (32). These optimum doses were used to determine the possible effects of ES and/or RT on ADAM and NEP activity in 4T1 and 4THMpc cells in the present study.

Activity of ADAM10 and NEP enzymes. Activity of ADAM10 and NEP were examined at the end of $24 \mathrm{~h}$ following ES and/or RT administration to investigate the association between the quantity of SP and the activity and/or quantity of these enzymes. To characterize the activity of ADAM10 responsible for SP cleavage, $\alpha$-secretase activity in the $4 \mathrm{~T} 1$ and 4THMpc cell lines was investigated by enzyme-linked immunosorbent assay using a TACE inhibitor (TAPI). According to the results, ES alone did not alter basal $\alpha$-secretase activity of 4T1 cells $(\mathrm{P}>0.05)$. RT alone resulted in a marked increase in $\alpha$-secretase activity $(\mathrm{P}<0.05)$. However, the increase in enzyme activity was greater $(\mathrm{P}<0.01)$ with administration of $\mathrm{ES}$ and RT together (Fig. 1). The 4THMpc cells treated with ES, RT or $\mathrm{ES}+\mathrm{RT}$ were demonstrated to already have a high basal level of $\alpha$-secretase compared with the 4T1 cells. By contrast to the 4T1 cells, ES $(\mathrm{P}<0.05)$, RT $(\mathrm{P}<0.01)$ and $\mathrm{ES}+\mathrm{RT}(\mathrm{P}<0.01)$ increased the activity of $\alpha$-secretase in 4THMpc cells (Fig. 2).

The basal level of NEP enzyme activity was higher in 4T1 cells compared with 4THMpc cells. As presented in Fig. 3, in 4T1 cells ES alone did not alter NEP activity $(\mathrm{P}>0.05)$. However, RT alone resulted in a significant decrease in NEP activity of 4T1 cells $(\mathrm{P}<0.01)$. RT + ES resulted in a significant increase in NEP activity $(\mathrm{P}<0.05)$. In 4THMpc cells, ES alone did not alter NEP activity $(\mathrm{P}>0.05)$, however RT alone or in combination produced a decrease in NEP activity $(\mathrm{P}<0.05$; Fig. 4).

Western blotting. To determine whether changes in NEP and ADAM10 activity in 4T1 and 4THMpc cells were due to changes in NEP and ADAM10 protein expression levels, cell homogenates were assayed by western blotting. As presented in Figs. 5 and 6, the density of the bands depend on the quantity of ADAM10 or NEP, thus, correlating with the activity of the enzymes. ES alone did not change the amount of ADAM10 in 4T1 cells but RT alone resulted in an increased amount of the enzyme. However, the increase in the amount of ADAM10 was greater following combinaiton with ES and RT, compared with either alone. Treatment of the 4THMpc cells with ES led to an increase in ADAM10 but this increase was greater in cells treated with the combination of ES and RT.

In 4T1 cells, ES alone did not alter the amount of NEP while RT alone resulted in a decrease, the combination of RT and ES resulted in a marked increase in the amount of NEP. In 4THMpc cells, RT alone or in combination with ES resulted in a decrease in the amount of NEP; however, ES treatment alone did not yield any change in NEP. 


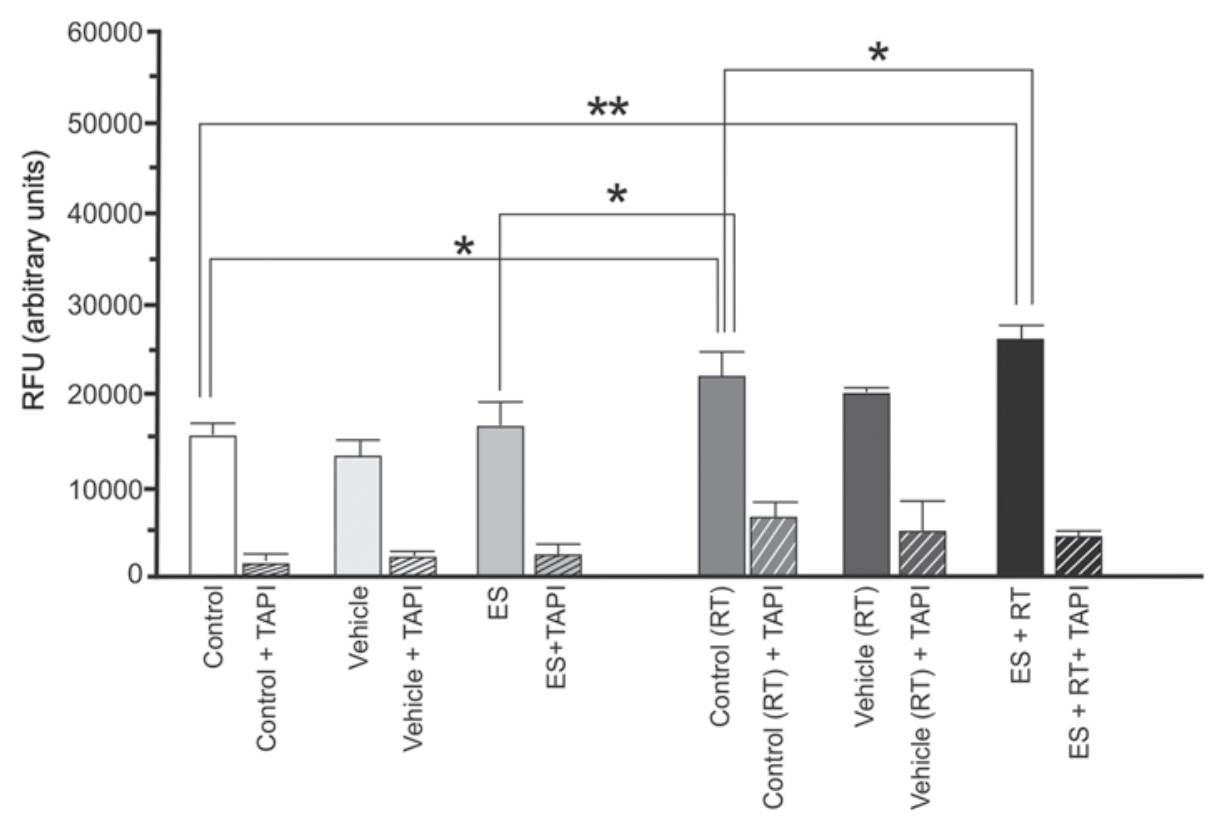

Figure 1. Effects of ES and/or RT on ADAM10 activity of 4T1 cells were determined by measuring $\alpha$-secretase activity. A tumour necrosis factor- $\alpha$ convertase inhibitor (TAPI) was used at $1 \mu \mathrm{M}$ concentration as inhibitor control. Although there were no difference in ADAM10 activity between control and ES treated $4 \mathrm{~T} 1$ cells, the combination of ES and RT significantly increased ADAM10 activity $(\mathrm{P}<0.01)$. The differences between in the ADAM10 activity of the groups were evaluated using analysis of variance followed by the Tukey-Kramer post-hoc test. " $\mathrm{P}<0.05$; ${ }^{* *} \mathrm{P}<0.01$. ES, endostatin; RT, radiotherapy; ADAM10, a disintegrin and metalloproteinase domain-containing protein 10 ; RFU, relative fluorescence units; TAPI, TNF- $\alpha$ processing inhibitor.

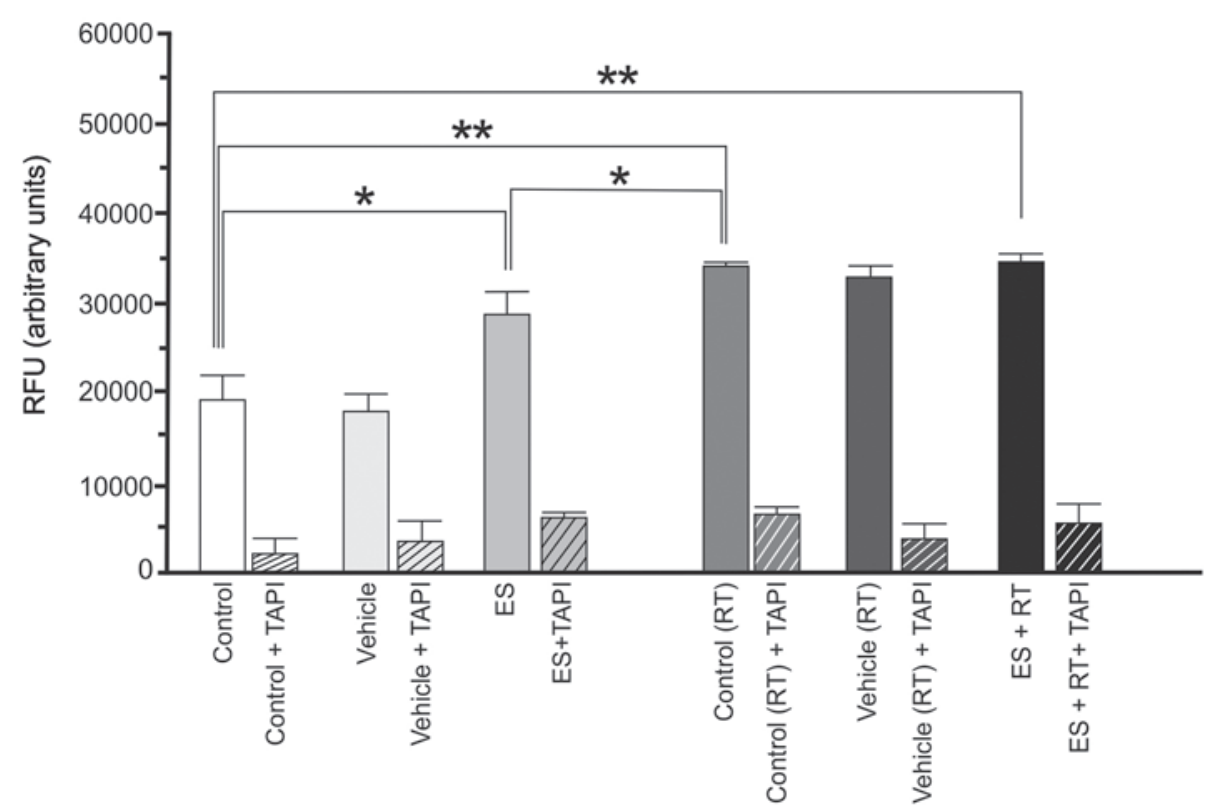

Figure 2. Effects of ES and/or RT on ADAM10 activity of 4THMpc cells were determined by measuring $\alpha$-secretase activity. A tumour necrosis factor- $\alpha$ convertase inhibitor (TAPI) was used at $1 \mu \mathrm{M}$ concentration as inhibitor control. In 4THMpc cells, a more aggressive form of 4T1 cells, ES, RT and the combination treatment significantly increased ADAM10 activity. The differences between ADAM10 activity of the groups were evaluated with analysis of variance followed by the Tukey-Kramer post-hoc test " $\mathrm{P}<0.05 ;{ }^{* *} \mathrm{P}<0.01$. ES, endostatin; RT, radiotherapy; ADAM10, a disintegrin and metalloproteinase domain-containing protein 10; RFU, relative fluorescence units; TAPI, TNF- $\alpha$ processing inhibitor.

\section{Discussion}

The internal fragment of collagen XVIII, ES, has been demonstrated to inhibit in vitro endothelial proliferation, but not tumor cell proliferation, suggesting that ES has endothelial cell specific activity $(34,35)$. Previous in vivo studies have indicated that ES inhibits growth of primary tumors by inhibiting tumor angiogenesis without directly affecting the growth of tumor cells $(5,6)$. These in vitro and in vivo studies suggest that ES does not have a direct cytotoxic effect on tumor cells. However, Dkhissi et al (36) have demonstrated that ES has direct anti-proliferative and apoptotic effects on HT29 and C51 colon cancer cell lines in addition to its anti-angiogenic effect. Similarly, Hanai et al (37) reported that 


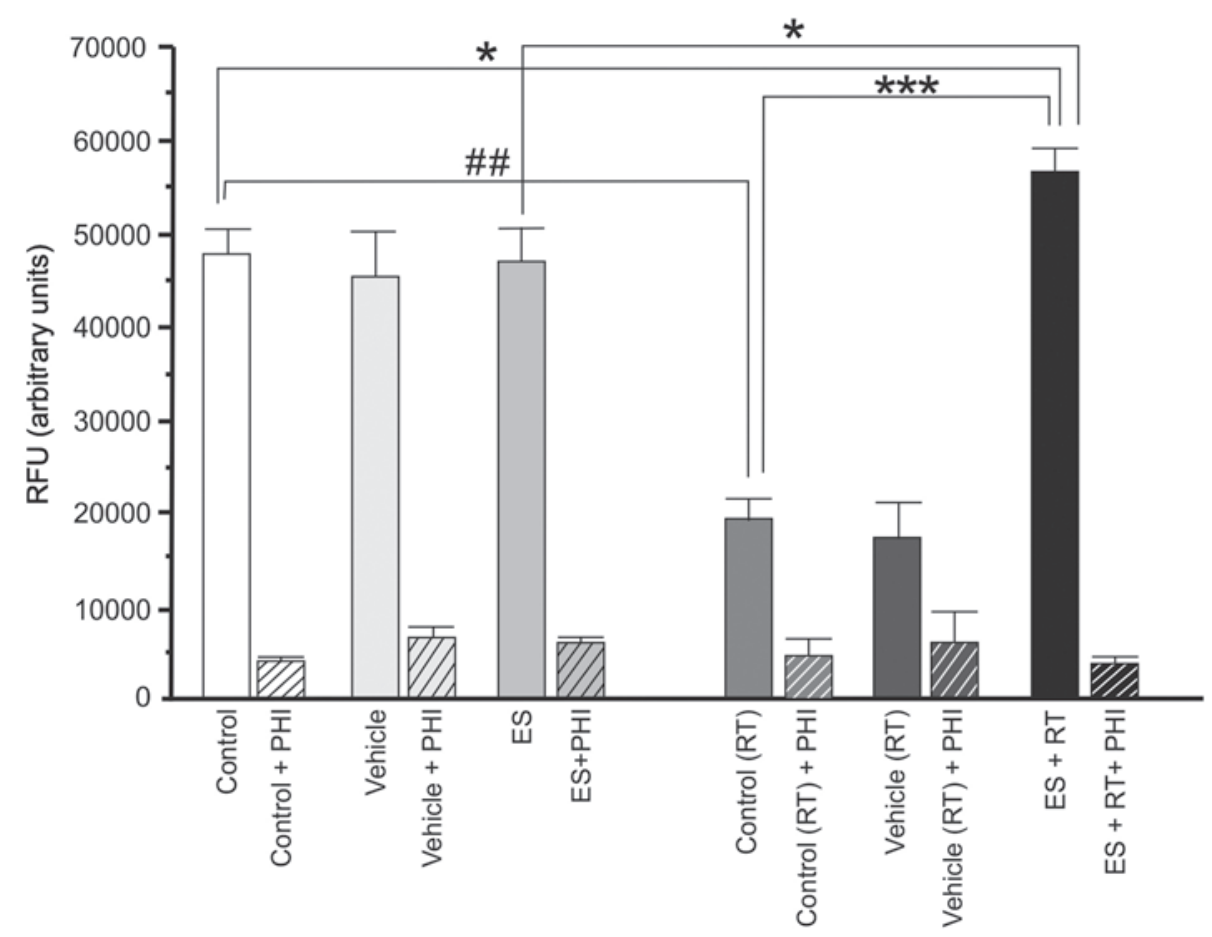

Figure 3. Differences between NEP activities of 4T1 cells. PHI was used as inhibitor of NEP. RT alone significantly decreased NEP activity of 4T1 cells $(\mathrm{P}<0.01)$. The effect of combination treatment on NEP activity of $4 \mathrm{~T} 1$ was significantly increased $(\mathrm{P}<0.05)$. The differences between NEP activity of tested groups were evaluated with analysis of variance followed by the Tukey-Kramer post-hoc test. ${ }^{*} \mathrm{P}<0.05$ and ${ }^{* * * *} \mathrm{P}<0.001$, indicating an increase in enzyme activity. ${ }^{\# \#} \mathrm{P}<0.01$, indicating a decrease in NEP activity. NEP, neprilysin; PHI, phosphoramidon; RT, radiotherapy; ES, endostatin; RFU, relative fluorescence units.

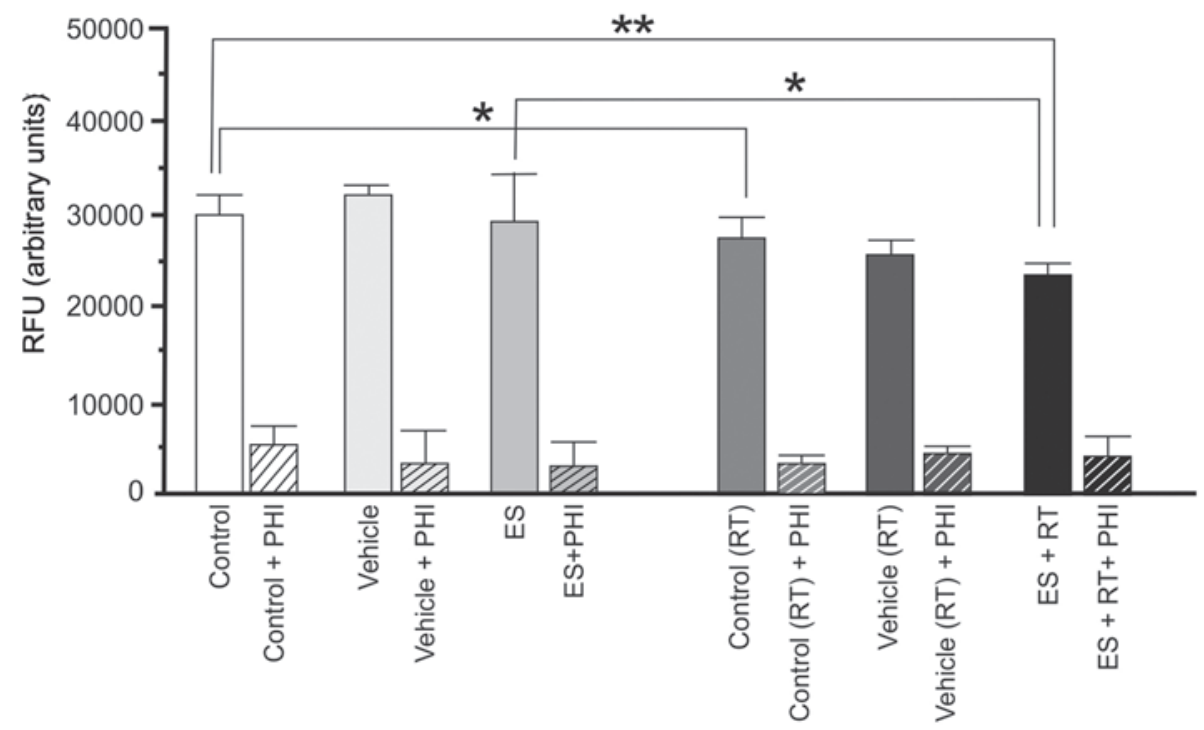

Figure 4. Differences between NEP activities of 4THMpc cells. PHI was used as inhibitor of NEP. ES did not alter NEP activity, RT alone and in combination with ES significantly decreased the NEP activity $(\mathrm{P}<0.05$ and $\mathrm{P}<0.01$ respectively) of 4THMpc cells. The differences between NEP activity of the groups were evaluated with analysis of variance followed by the Tukey-Kramer post-hoc test. ${ }^{*} \mathrm{P}<0.05$ and ${ }^{* * *} \mathrm{P}<0.01$. NEP, neprilysin; PHI, phosphoramidon; ES, endostatinRT, radiotherapy; RFU, relative fluorescence units.

ES inhibited the Wnt-dependent signaling pathway by stimulating the degradation of $\beta$-catenin in endothelial cells and in DLD-1 colon cancer cells. Furthermore, Hajitou et al (38) have demonstrated that ES inhibits in vitro EF43.Fgf-4 mouse breast cancer cell proliferation via the inhibition of VEGF expression (38). Due to these different activities, ES exhibits a multifaceted anti-angiogenic effect. In our initial study, it was reported that ES at appropriate doses and incubation periods exerted cytotoxic and apoptotic effects against 4T1 and 4THMpc cells. These results regarding the cytotoxic effects of ES to tumor cells appeared to be contrary to the general considerations, however, the results were consistent with findings that demonstrate direct cytotoxic effects of ES on tumor cells. It was previously indicated that that the cytotoxic effect 


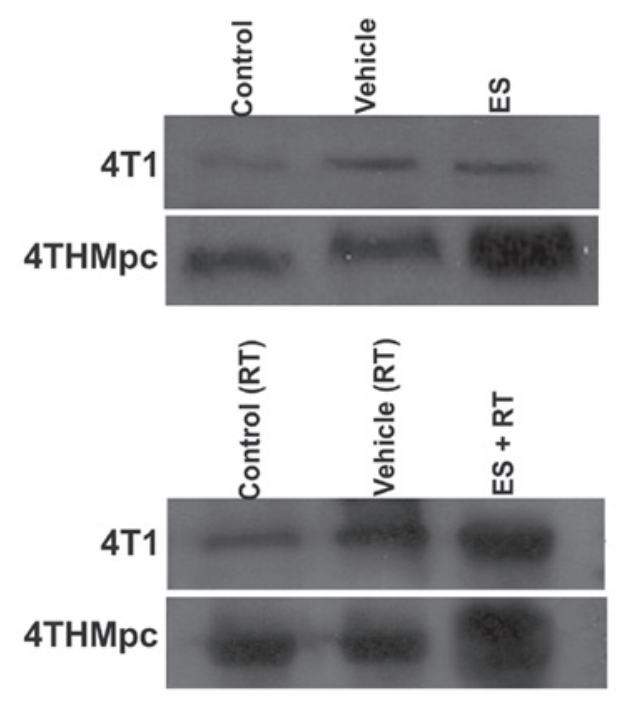

Figure 5. Amount of $97 \mathrm{kDa}$ ADAM10 was analyzed in cell lysates from 4T1 and 4THMpc cells treated with ES and/or RT by western blotting. The thickness or thinness of visualized bands is associated with the $\alpha$-secretase activity of ADAM10. ADAM10, a disintegrin and metalloproteinase domain-containing protein 10; ES, endostatin; RT, radiotherapy.

of ES on tumor cells depends on a minimum of four factors, as follows: i) The concentration of ES, ii) the type of targeted cell, iii) the time period of incubation and iv) the number of tested cells (32).

Combinations of different therapies may repress the multifactor stimulated biological processes of tumors, and result in cytoxicity. At present, anti-cancer research is investigating the success of radiotherapy and angiogenesis inhibitors together $(39,40)$. Different scientists have demonstrated that combination of radiotherapy and angiogenesis inhibitors may result in either additive or synergistic effects. Previous studies suggest that the addition of anti-angiogenic agents to conventional therapeutic strategies may increase clinical efficacy $(39,41,42)$. Previous studies suggest that the addition of anti-angiogenic agents to conventional therapeutic strategies may increase clinical efficacy $(39,43,44)$. As radiation therapy is a conventional cancer treatment strategy, tumor resistance to ionizing radiation has been previously investigated. The interactions between exposure to ionizing radiation and anti-angiogenic treatment may result in an improved understanding of effective cancer therapy with these treatments (43).

In the present study, the possible effects of $4 \mu \mathrm{g} / \mathrm{ml} \mathrm{ES}$, either alone or in combination with $45 \mathrm{~Gy}{ }^{60} \mathrm{Co}$ irradiation, on the expression levels and activity of NEP and ADAM-10 were investigated. NEP and ADAM10 degrade SP at the same point. SP, a member of the tachykinin family is suggested to be predominantly localized in sensory nerves and around blood vessels and smooth muscle (20). The role of SP in cancer development and progression is likely bidirectional, with intact peptide and hydrolysis products exerting different effects $(20,23,45)$. Bidirectional effects of SP on carcinogenesis may be the result of the counter-balancing effects of SP fragments compared with the intact peptide, as the intact peptide is tumorigenic and induces inflammation, whereas fragments produced by peptidases (including, neprilysin and ADAM10) exert opposing effects $(23,46,47)$.

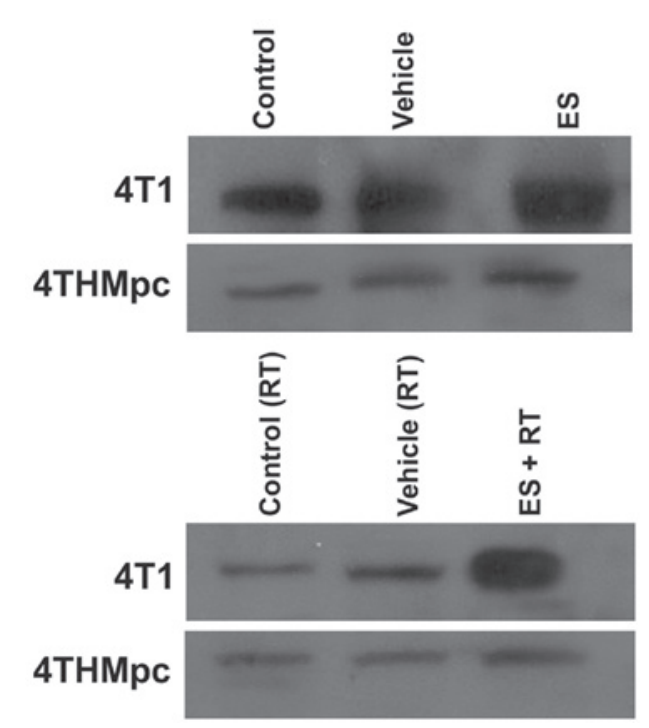

Figure 6. Amount of $95 \mathrm{kDa}$ neprilysin was analyzed in cell lysates from 4T1 and 4THMpc cells treated with ES and/or RT by western blotting. ES, endostatin; RT, radiotherapy.

A disintegrin and metalloproteases (ADAMs) are a family of metalloproteases (48), with important functions in a variety of different biological processes, including the interaction of sperm and egg, cell migration, wound healing, heart development, immunity, cell proliferation and angiogenesis (49). ADAM-10 and TACE (ADAM17) have been proposed as an $\alpha$-secretase (50). ADAM10 sheds a number of cell surface proteins, including TNF- $\alpha$, epidermal growth factor (EGF), TGF- $\alpha$, and heparin-binding EGF-like growth factor. Furthermore, ADAM10 mediates regulated intramembrane proteolysis of CD44, cadherins and Notch, which produce an intracellular fragment that can influence gene transcription following translocation to the nucleus (51). Overexpression of ADAM family members (51), including ADAM10 (52), has been reported in different malignancies.

In 4T1 cells, ES alone did not alter the activity or the protein expression level of ADAM10. RT ( $45 \mathrm{~Gy}{ }^{60} \mathrm{Co}$ ) alone induced a 55\% increase in ADAM10 enzyme activity and this activation increased to $74.5 \%$ when combined therapy was used. By contrast, in the 4THMpc cell line, ES alone induced a $43.3 \%$ increase in ADAM10 enzyme activity, while RT alone and with ES resulted in an increase of 70.9 and $72.5 \%$ in ADAM10 activity, respectively.

NEP is a zinc-dependent type II integral membrane-bound metallopeptidase with ubiquitous distribution that is demonstrated to cleave a variety of peptides, including natriuretic. peptides, angiotensin-I and -II, endothelin-1, kinins, adrenomedullin, opioid peptides, bradykinin, bombesin, calsistonine, neurotensin, substance $\mathrm{P}, \mathrm{A} \beta$, enkephalin, and gastrin $(14,52-54)$. This enzyme is also observed in various tissues, however, it has highest abundance in the kidney (53). Recently, it has been suggested that NEP activity and/or expression levels are decreased in different carcinomas, including prostate (19), lung (55), renal (56) and stomach and colon adenocarcinomas $(17,53,57)$. By contrast, high levels of NEP were also indicated in a malignant hepatocellular carcinomas $(17,58,59)$. Furthermore, Burns et al (19) suggested that 
NEP modulates bombesin-mediated proliferation in breast cancer cells in vitro.

In the present study, in 4T1 cells, ES alone slightly increased NEP activity by $7.54 \%$, however, this is not a statistically significant result. While RT alone resulted in $60 \%$ decrease, $\mathrm{ES}+\mathrm{RT}$ resulted in a $16.6 \%$ increase in NEP activity. In the more aggressive 4THMpc cells, administration of ES alone led to a $14.2 \%$ increase in NEP activity. RT treatment and $\mathrm{ES}+\mathrm{RT}$ in combination resulted in a 6.6 and $8.3 \%$ decrease in enzyme activity, respectively.

Considering our previous study (32), the present study hypothesized that ES interfered with angiogenesis indirectly by altering the quantity of SP in breast cancer cells by modulating the activity of ADAM10 and NEP. To investigate whether cell death was a result of differences in SP levels due to changes in ADAM10 and NEP activity, 4T1 and 4THMpc cells were treated with $4 \mu \mathrm{g} / \mathrm{ml}$ exogenous SP, either with ES, RT or alone (32). The growth inhibition of these two cancer cell lines was also partially reversed by administration of exogenous SP concomitantly with ES and RT, whereas exogenous SP alone enhances cell viability rather than cell death. Further experiments determined that exogenous SP alone did not result in cell death or changes to the activity of ADAM10 and NEP. This result indicates that the action of the ES on 4T1 and 4THMpc cells is associated with the activation of SP-degrading enzymes, ADAM10 and NEP. The results of the present study are in agreement with the findings of previous studies, in which the use of SP antagonists inhibited in vitro growth of small cell lung cancer and the U373 MG glioma cell line (60-65). Gross et al (66) demonstrated that SP reduces caspase- 3 activity and TNF- $\alpha$-induced apoptosis. Caspase-3 activity was markedly increased following treatment with ES and RT. If SP had remained unchanged in the 4T1 and 4THMpc cells or the media, it would not have been possible to record the increase in caspase-3 activity (32). The results of our previous study and the current study suggest that the cytotoxic activity of ES on 4T1 and 4THMpc cells is a specific, dose-dependent action, which alters the activity of ADAM10 and NEP, and SP levels. The level of SP is an important determinants for tumor cells to increase mitotic signals. Different changes in SP levels following ES, RT and the combination treatment were recorded (32), suggesting the cytotoxic activity of ES occurs due to the changes in ADAM10 and NEP activity. ES and RT used in combination affects the activation of ADAM10 and NEP and once these peptidases are activated, they may degrade SP at the same point producing short fragments. Finally, these fragments may trigger the activation of caspase- 3 and result in apoptosis of the 4T1 and 4THMpc cells.

In conclusion, the present study demonstrates for the first time that ES potentiates the activity of ADAM10 and NEP. The current study hypothesizes that the recorded cytotoxic activity of ES on 4T1 and 4THMpc breast cancer cells is likely associated with altering the activity of these peptidases. Further in vitro and in vivo studies are required to elucidate the suggested underlying mechanism and to increase understanding of whether ES exert cytotoxic effect via the fragmented SP, which results from activating these peptidases. Furthermore, in addition to its cytotoxic and antiangiogenic effects, the ability of ES to increase the quantity and activity of ADAM10 may be valuable in the treatment of AD.

\section{Acknowledgements}

The present study was supported by The Scientific and Technological Research Council of Turkey (grant no. $107 \mathrm{~T}$ 204). The authors would like to thank Dr Nina Tuncel and all the technicians of the Department of Radiation Oncology for their technical assistance; all the employees of Akdeniz University Research Unit under the leadership of Professor Olcay Yeğin for their support throughout the present study; Professor B. Uğur Yavuzer for her thoughtful comments and suggestions on the western blotting results; and Ms. Duygu Sahintürk Ünal for her excellent technical assistance.

\section{References}

1. Hanahan D and Folkman J: Patterns and emerging mechanisms of the angiogenic switch during tumorigenesis. Cell 86: 353-364, 1996.

2. Pieraccini S, Saladino G, Sironi M, Francescato P, Cattaneo MG, Vicentini LM, Speranza G and Manitto P: A molecular dynamics study of an endostatin-derived peptide with antiangiogenic activity and of its mutants. Chem Phys Lett 455: 311-315, 2008.

3. Wang Z, Dabrosin C, Yin X, Fuster MM, Arreola A, Rathmell WK, Generali D, Nagaraju GP, El-Rayes B, Ribatti D, et al: Broad targeting of angiogenesis for cancer prevention and therapy. Semi Cancer Biol 35 (Suppl): S224-S243, 2015.

4. Shimizu K and Oku N: Cancer anti-angiogenic therapy. Biol Pharm Bull 27: 599-605, 2004.

5. O'Reilly MS, Boehm T, Shing Y, Fukai N, Vasios G, Lane WS, Flynn E, Birkhead JR, Olsen BR and Folkman J: Endostatin: An endogenous inhibitor of angiogenesis and tumor growth. Cell 88: 277-285, 1997.

6. Zatterstrom UK, Felbor U, Fukai N and Olsen BR: Collagen $\mathrm{XVIII} / \mathrm{endostatin}$ structure and functional role in angiogenesis. Cell Struct Funct 25: 97-101, 2000

7. Dhanabal M, Ramchandran R, Waterman MJ, Lu H, Knebelmann B, Segal M and Sukhatme VP: Endostatin induces endothelial cell apoptosis. J Biol Chem 274: 11721-11726, 1999.

8. Rehn M, Veikkkola T, Kukk-Valdre E, Nakamura H, Ilmonen M, Lombardo C, Pihlajaniemi T, Alitalo K and Vuori K: Interaction of endostatin with integrins implicated in angiogenesis. Proc Natl Acad Sci USA 98: 1024-1029, 2001.

9. Kim YM, Hwang S, Kim YM, Pyunn BJ, Kim TY, Lee ST, Gho YS and Kwon YG: Endostatin blocks vascular endthelial growth factor-mediated signaling via direct interaction with KDR/Flk-1. J Biol Chem 277: 27872-27879, 2002.

10. Hanai J, Dhanabal M, Karumanchi SA, Albanese C, Waterman M, Chan B, Ramchandran R, Pestell R and Sukhatme VP: Endostatin causes G1 arrest of endothelial cells through inhibition of cyclin D1. J Biol Chem 277: 16464-16469, 2002.

11. Kim YM, Jang JW, Lee OH, Yeon J, Choi EY, Kim KW, Lee ST and Kwon YG: Endostatin inhibits endothelial and tumor cellular invasion by blocking the activation and catalytic activity of matrix metalloproteinase. Cancer Res 60: 5410-5413, 2000.

12. Lee SJ, Jang JW, Kim YM, Lee HI, Jeon JY, Kwon YG and Lee ST: Endostatin binds to the catalytic domain of matrix metalloproteinase-2. FEBS Lett 519: 147-152, 2002.

13. Foda HD and Zucker S: Matrix metalloproteinases in cancer invasion, metastasis and angiogenesis. Drug Discov Today 6: 478-482, 2001

14. Hellström-Lindahl E, Ravid R and Nordberg A: Age-dependent decline of neprilysin in Alzheimer's disease and normal brain: Inverse correlation with A beta levels. Neurobiol Aging 29: 210-221, 2008.

15. Bunn PA Jr, Helfrich BA, Brenner DG, Chan DC, Dykes DJ, Cohen AJ and Miller YE: Effects of recombinant neutral endopeptidase (EC 3.4.24.11.) on the growth of lung cancer cell lines in vitro and in vivo. Clin Cancer Res 4: 2849-2858, 1998. 
16. Usmani BA, Harden B, Maitland NJ and Turner AJ: Differential expression of neutral endopeptidase-24.11 (neprilysin) and endothelin-converting enzyme in human prostate cancer cell lines. Clin Sci (Lond) 103 (Suppl 48): 314S-317S, 2002.

17. Renneberg H, Albrecht M, Kurek R, Krause E, Lottspeich F, Aumüller $\mathrm{G}$ and Wilhelm B: Identification and characterization of neutral endopeptidase (EC 3.4.24.11) from human prostasomes-localization in prostatic tissue and cell lines. Prostate 46: 173-183, 2001.

18. Albrecht M, Doroszewicz J, Gillen S, Gomes I, Wilhelm B, Stief T and Aumüller G: Proliferation of prostate cancer cells and activity of neutral endopeptidase is regulated by bombesin and IL-Ibeta with IL-1beta acting as a modulator of cellular differentiation. Prostate 58: 82-94, 2004.

19. Burns DM, Walker B, Gray J and Nelson J: Breast cancer cell associated endopeptidase EC 24.11 modulates proliferative response to bombesin. Br J Cancer 79: 214-220, 1999.

20. Seals DF and Courtneidge SA: The ADAMs family of metalloproteinases: Multidomain proteins with multiple functions Genes Dev 17: 7-30, 2003.

21. Van der Vorst EP, Keijbeck AA, de Winther MP and Donners MM: A disintegrin and metalloproteases: Molecular scissors in angiogenesis, inflammation and atherosclerosis. Atherosclerosis 224 302-308, 2012

22. Mochizuki S and Okada Y: ADAMs in cancer cell proliferation and progression. Cancer Sci 98: 621-628, 2007.

23. Erin N, Zhao W, Bylander J, Chase G and Clawson G: Capsaicin induced inactivation of sensory neurons promotes a more aggressive gene expression phenotype in breast cancer cells. Breast Cancer Res Treat 99: 351-364, 2006.

24. Sumner SC, Gallagher KS, Davis DG, Covell DG, Jernigan RL and Ferretti JA: Conformational analysis of the tachykinins in solution: Substance P and physalaemin. J Biomol Struct Dyn 8: 687-707, 1990

25. Kurtz MM, Wang R, Clements MK, Cascieria MA, Austin CP, Cunningham BR, Chicchia GG and Liu Q: Identification, localization and receptor characterization of novel mammalian substance P-like peptides. Gene 296: 205-212, 2002.

26. Koon HW and Pothoulakis C: Immunomodulatory properties of substance P: The gastrointestinal system as a model. Ann NY Acad Sci 1088: 23-40, 2006

27. Schäffer M, Beiter T, Becker HD and Hunt TK: Neuropeptides: Mediators of inflammation and tissue repair? Arch Surg 133: 1107-1116, 1998.

28. Muangman P, Tamura RN, Muffley LA, Isik FF, Scott JR, Xie C, Kegel G, Sullivan SR, Liang Z and Gibran NS: Substance P enhances wound closure in nitric oxide synthase knockout mice. J Surg Res 153: 201-209, 2009.

29. Chappa AK, Audus KL and Lunte SM: Characteristics of substance P transport across the blood-brain barrier. Pharm Res 23: 1201-1208, 2006

30. Esteban F, Gonzalez-Moles MA, Castro D, Martin-Jaen Mdel M, Redondo M, Ruiz-Avila I and Muñoz M: Expression of substance $P$ and neurokinin-1-receptor in laryngeal cancer: Linking chronic inflammation to cancer promotion and progression. Histopathology 54: 258-260, 2009.

31. Erin $\mathrm{N}$ and Ulusoy O: Differentiation of neuronal from non-neuronal substance P. Regul Pept 152: 108-113, 2009.

32. Arslan Aydemir E, Simsek Oz E, Fidan Korcum A and Fiskin K: Endostatin enhances radioresponse in breast cancer cells via alteration of substance P levels. Oncol Lett 2 879-886, 2011

33. Carpenter TC and Stenmark KR: Hypoxia decreases lung neprilysin express and increases pulmonary vascular leak. Am J Physiol Lung Cell Mol Physiol 281: L941-L948, 2001.

34. Shichiri M and Hirata Y: Antiangiogenesis signals by endostatin. FASEB J 15: 1044-1053, 2001.

35. Kranenburga O, Kroon-Batenburgb LM, Reijerkerka A, Wuc YP, Voesta EE and Gebbinka MF: Recombinant endostatin forms amyloid fibrils that bind and are cytotoxic to murine neuroblastoma cells in vitro. FEBS Lett 539: 149-155, 2003.

36. Dkhissi F, Lu H, Sorı C, Opolon P, Griscelli F, Liu H, Khattar P, Mishal Z, Perricaudet M and Li H: Endostatin exhibits a direct antitumor effect in addition to its antiangiogenic activity in colon cancer cells. Hum Gene Ther 14: 997-1008, 2003.

37. Hanai J, Gloy J, Karumanchi SA, Kale S, Tang J, Hu G, Chan B, Ramchandran R, Jha V, Sukhatme VP and Sokol S: Endostatin is a potential inhibitor of Wnt signaling. J Cell Biol 158: 529-539, 2002 .
38. Hajitou A, Grignet C, Devy L, Berndt S, Blacher S, Deroanne CF, Bajou K, Fong T, Chiang Y, Foidart JM and Noël A: The antitumoral effect of endostatin and angiostatin is associated with a down-regulation of vascular endothelial growth factor expression in tumor cells. FASEB J 16: 1802-1804, 2002.

39. Verhoef C, de Wilt JH and Verheul HM: Angiogenesis inhibitors: Perspectives for medical, surgical and radiation oncology. Curr Pharma Design 12: 2623-2630, 2006.

40. Higgins GS, O'Cathail SM, Muschel RJ and McKenna WG: Drug radiotherapy combinations: Review of previous failures and reasons for future optimism. Cancer Treat Rev 41: 105-113, 2015.

41. Teicher BA: A systems approach to cancer therapy. (Antioncogenics + standard cytotoxics $\rightarrow$ mechanism(s) of interaction). Cancer Metastasis Rev 15: 247-272, 1996.

42. Zips D, Krause M, Hessel F, Westphal J, Brüchner K, Eicheler W, Dörfler A, Grenman R, Petersen C, Haberey M and Baumann M: Experimental study on different combination schedules of VEGF-receptor inhibitor PTK787/ZK222584 and fractionated irradiation. Anticancer Res 23: 3869-3876, 2003.

43. Kaliski A, Maggiorella L, Cengel KA, Mathe D, Rouffiac V, Opolon P, Lassau N, Bourhis J and Deutsch E: Angiogenesis and tumor growth inhibition by a matrix metalloproteinase inhibitor targeting radiation-induced invasion. Mol Cancer Ther 4: 1717-1728, 2005

44. Dass CR, Tran TM and Choong PF: Angiogenesis Inhibitors and the need for anti-angiogenic therapeutics. J Dent Res 86: 927-936, 2007.

45. Luo W, Sharif TR and Sharif M: Substance P-induced mitogenesis in human astrocytoma cells correlates with activation of the mitogen-activated protein kinase signaling pathway. Cancer Res 56: 4983-4991, 1996.

46. Muñoz M, Pérez A, Rosso M, Zamarriego C and Rosso R: Antitumoral action of the neurokinin-1 receptor antagonist L-733 060 on human melanoma cell lines. Melanoma Res 14: 183-188, 2004.

47. Walsh DT, Weg VB, Williams TJ and Nourshargh S: Substance $P$ induced inflammatory responses in guinea-pig skin: The effect of specific NK1 receptor antagonists and the role of endogenous mediators. Br J Pharmacol 114: 1343-1350, 1995.

48. Musumecia G, Coleman R, Imbesi R, Magro G, Parenti R, Szychlinska MA, Scuderi R, Cinà CS, Castorina $S$ and Castrogiovanni P: ADAM-10 could mediate cleavage of $\mathrm{N}$-cadherin promoting apoptosis in human atherosclerotic lesions leading to vulnerable plaque: A morphological and immunohistochemical study. Acta Histochem 116: 1148-1158, 2014.

49. Reiss K and Saftig P: The 'a disintegrin and metalloprotease' (ADAM) family of sheddases: Physiological and cellular functions. Semin Cell Dev Biol 20: 126-137, 2009.

50. Li B, Yu D and Xu Z: Activated protein C inhibits amyloid $\beta$ production via promoting expression of ADAM-10. Brain Res 1545: 35-44, 2014

51. Jones AV, Lambert DW, Speight PM and Whawell SA: ADAM 10 is over expressed in oral squamous cell carcinoma and contributes to invasive behaviour through a functional association with $\alpha v \beta 6$ integrin. FEBS Lett 587: 3529-3534, 2013.

52. Simsek E, Aydemir E, Korcum AF and Fiskin K: Thalidomide combined with irradiation alters the activity of two proteases. Mol Med Rep 11: 1535-1541, 2015.

53. von Lueder TG, Atar D and Kruma H: Current role of neprilysin inhibitors in hypertension and heart failure. Pharmacol Ther 144: 41-49, 2014

54. Bayés-Genís A, Barallat J, Galán A, de Antonio M, Domingo M, Zamora E, Urrutia A and Lupón J: Soluble neprilysin is predictive of cardiovascular death and heart failure hospitalization in heart failure patients. J Am Coll Cardiol 65: 657-665, 2015.

55. Cohen AJ, Bunn PA, Franklin W, Magill-Solc C, Hartmann C, Helfrich B, Gilman L, Folkvord J, Helm K and Miller YE: Neutral endopeptidase: Variable expression in human lung, inactivation in lung cancer, and modulation of peptide-induced calcium flux. Cancer Res 56: 831-839, 1996.

56. Göhring B, Holzhausen HJ, Meye A, Heynemann H, Rebmann U, Langner J and Riemann D: Endopeptidase 24.11/CD10 is down-regulated in renal cell cancer. Int J Mol Med 2: 409-414, 1998

57. Sato Y, Itoh F, Hinoda Y, Ohe Y, Nakagawa N, Ueda R, Yachi A and Imai K: Expression of CD10/neutral endopeptidase in normal and malignant tissues of the human stomach and colon. J Gastroenterol 31: 12-17, 1996.

58. Dragović T, Deddish PA, Tan F, Weber G and Erdös EG: Increased expression of neprilysin (neutral endopeptidase 24.11) in rat and human hepatocellular carcinomas. Lab Invest 70: 107-113, 1994. 
59. Dragovic T, Sekosan M, Becker RP and Erdös EG: Detection of neutral endopeptidase 24.11 (neprilysin) in human hepatocellular carcinomas by immunocytochemistry. Anticancer Res 17: 3233-3238, 1997.

60. Esteban F, Muñoz M, González-Moles MA and Rosso M: A role for substance $\mathrm{P}$ in cancer promotion and progression: A mechanism to counteract intracellular death signals following oncogene activation or DNA damage. Cancer Metastasis Rev 25: 137-145, 2006.

61. Langdon S, Sethi T, Ritchie A, Muir M, Smyth J and Rozengurt E: Broad spectrum neuropeptide antagonists inhibit the growth of small celllung cancer in vivo. Cancer Res 52: 4554-4557, 1992

62. Reeve JG and Bleehen NM: D-Arg ${ }^{1}, \mathrm{D}-\mathrm{Phe}^{5}, \mathrm{D}-\mathrm{Trp}^{7,9}, \mathrm{Leu}^{11}$ substance $\mathrm{P}$ induces apoptosis in lung cancer cell lines in vitro. Biochem Biophys Res Commun 199: 1313-1319, 1994.

63. Seckl MJ, Higgins T, Widmer F and Rozengurt E: D-Arg ${ }^{1}$, D-Trp ${ }^{5,7,9}$, Leu $^{11}$ substance P: A novel potent inhibitor of signal transduction and growth in vitro and in vivo in small cell lung cancer cells. Cancer Res 57: 51-54, 1997.
64. Woll PJ and Rozengurt E: D-Arg ${ }^{1}, \mathrm{D}_{-} \mathrm{Phe}^{5}$, D-Trp ${ }^{7,9}$, Leu ${ }^{11}$ substance $\mathrm{P}$, a potent bombesin antagonist in murine Swiss 3T3 cells, inhibits the growth of human small cell lung cancer cells in vitro. Proc Natl Acad Sci USA 85: 1859-1863, 1988.

65. Palma C, Bigioni M, Irrissuto C, Nardelli F, Maggi CA and Manzini S: Anti-tumour activity of tachykinin NK1 receptor antagonists on human glioma U373 MG xenograft. Br J Cancer 82: 480-487, 2000.

66. Gross K, Karagiannides I, Thomou T, Koon HW, Bowe C, Kim H, Giorgadze N, Tchkonia T, Pirtskhalava T, Kirkland JL and Pothoulakis C: Substance P promotes expansion of human mesenteric preadipocytes through proliferative and antiapoptotic pathways. Am J Physiol Gastrointest Liver Physiol 296: G1012-G1019, 2009. 